\title{
BMJ Open Implications of the introduction of new criteria for the diagnosis of gestational diabetes: a health outcome and cost of care analysis
}

Thomas J Cade, ${ }^{1,2,3}$ Alexander Polyakov, ${ }^{3,4}$ Shaun P Brennecke ${ }^{2,3}$

To cite: Cade TJ, Polyakov A, Brennecke SP. Implications of the introduction of new criteria for the diagnosis of gestational diabetes: a health outcome and cost of care analysis. BMJ Open 2019:9:e023293. doi:10.1136/ bmjopen-2018-023293

- Prepublication history for this paper is available online. To view these files, please visit the journal online (http://dx.doi. org/10.1136/bmjopen-2018023293).

Received 5 April 2018 Revised 7 November 2018 Accepted 8 November 2018

Check for updates

(C) Author(s) (or their employer(s)) 2019. Re-use permitted under CC BY-NC. No commercial re-use. See rights and permissions. Published by BMJ.

${ }^{1}$ Diabetes Service, Royal Women's Hospital, Parkville, Victoria, Australia

${ }^{2}$ Pregnancy Research Service, Department of Maternal Fetal Medicine, Royal Women's Hospital, Parkville, Victoria, Australia

${ }^{3}$ Department of Obstetrics and Gynaecology, University of

Melbourne, Parkville, Victoria, Australia

${ }^{4}$ Department of Reproductive Biology, Royal Women's Hospital, Parkville, Victoria, Australia

Correspondence to

Dr Thomas J Cade;

tom.cade@thewomens.org.au

\section{ABSTRACT}

Objective To identify effects on health outcomes from implementing new criteria diagnosing gestational diabetes mellitus(GDM) and to analyse costs-of-care associated with this change.

Design Quasi-experimental study comparing data from the calendar year before (2014) and after (2016) the change.

Setting Single, tertiary-level, university-affiliated, maternity hospital.

Participants All women giving birth in the hospital, excluding those with pre-existing diabetes or multiple pregnancy.

Main outcome measures Primary outcomes were caesarean section, birth weight $>90$ th percentile for gestation, hypertensive disorder of pregnancy and preterm birth less than 37 weeks. A number of secondary outcomes reported to be associated with GDM were also analysed. Care packages were derived for those without GDM, diet-controlled GDM and GDM requiring insulin. The institutional Business Reporting Unit data for average occasions of service, pharmacy schedule for the costs of consumables and medications, and Medicare Benefits Schedule ultrasound services were used for costing each package. All costs were estimated in figures from the end of 2016 negating the need to adjust for Consumer Price Index increases.

Results There was an increase in annual incidence of GDM of $74 \%$ without overall improvements in primary health outcomes. This incurred a net cost increase of AUD $\$ 560$ 093. Babies of women with GDM had lower rates of neonatal hypoglycaemia and special care nursery admissions after the change, suggesting a milder spectrum of disease.

Conclusion New criteria for the diagnosis of GDM have increased the incidence of GDM and the overall cost of GDM care. Without obvious changes in short-term outcomes, validation over other systems of diagnosis may require longer term studies in cohorts using universal screening and treatment under these criteria.

\section{INTRODUCTION}

Diagnostic criteria for gestational diabetes mellitus (GDM) in Australia changed following a 2014 consensus statement by the Australian Diabetes in Pregnancy Society
Strengths and limitations of this study

- Australia is one of the only major Western countries to introduce universal screening for gestational diabetes mellitus (GDM) by new International Association of Diabetes in Pregnancy Study Group criteria and is uniquely poised to assess concerns about increased annual incidence and costs of care compared with any potential improvement in health outcomes.

- Concerns about an increase in diagnoses and 'overmedicalisation' of women who erstwhile would have been considered normal have given many countries reason for caution in adopting the new criteria. Our findings may assist in decision-making regarding public health policy, although with findings applicable to clinical policy change within a single large centre. It may also highlight the need for longer term follow-up of women with GDM and their babies treated under this system.

- As with any large retrospective audit, there are potential methodological flaws in data analysis, including unrecognised selection bias and confounding. We have assessed the implication of adopting these criteria on a large entire cohort (not a specific subgroup) in an attempt to assess outcomes and costs as a surrogate for public health policy 'en masse'. Findings should be interpreted with respect to clinical policy change within a single centre and add to the debate about adopting this policy on a wider public scale.

- A major problem with assessing changes in diagnostic criteria in GDM lies within being unable to retrospectively identify those who were potentially underdiagnosed under older systems and assess their outcomes. We have thus assessed the impact on a large tertiary hospital as a whole and quantified the costs associated with the increased burden or care.

(ADIPS $)^{1}$ ratifying support for the International Association of Diabetes in Pregnancy Study Group's (IADPSG) recommendations ${ }^{2}$ (see table 1). These, in turn, used data from the Hyperglycaemia and Adverse Pregnancy 
Table 1 1991/1998 Australian Diabetes in Pregnancy Society (ADIPS) versus 2014 International Association of Diabetes in Pregnancy Study Group (IADPSG) criteria for diagnosing gestational diabetes mellitus

\begin{tabular}{|c|c|c|c|c|c|c|}
\hline & 1991/1998 ADIPS & \multirow[b]{2}{*}{ Positive criteria } & \multirow{2}{*}{$\begin{array}{l}2014 \text { IADPSG } \\
\text { Type of test }\end{array}$} & \multirow{2}{*}{$\begin{array}{l}\text { Positive } \\
\text { criteria }\end{array}$} & \multirow{2}{*}{$\begin{array}{l}2015 \text { NICE } \\
\text { Type of test }\end{array}$} & \multirow[b]{2}{*}{ Positive criteria } \\
\hline & Type of test & & & & & \\
\hline $\begin{array}{l}\text { Screening } \\
\text { test }\end{array}$ & $\begin{array}{l}50 \mathrm{~g} \text { non-fasting glucose } \\
\text { challenge test or } \\
75 \mathrm{~g} \text { non-fasting glucose } \\
\text { challenge test }\end{array}$ & $\begin{array}{l}\geq 7.8 \mathrm{mmol} / \mathrm{L} \\
\geq 8.0 \mathrm{mmol} / \mathrm{L}\end{array}$ & Nil & $\begin{array}{l}\text { Not } \\
\text { applicable (N) }\end{array}$ & $\begin{array}{l}\text { Clinical risk } \\
\text { assessment }\end{array}$ & $\begin{array}{l}\text { Any one of five } \\
\text { clinical risk } \\
\text { factors }^{9}\end{array}$ \\
\hline $\begin{array}{l}\text { Diagnostic } \\
\text { test }\end{array}$ & $\begin{array}{l}75 \mathrm{~g}, 2 \text { hours fasting } \\
\text { glucose tolerance test } \\
\text { (two levels) }\end{array}$ & $\begin{array}{l}\text { Fasting } \\
\geq 5.5 \mathrm{mmol} / \mathrm{L} \\
2 \text { hours } \\
\geq 8.0 \mathrm{mmol} / \mathrm{L}\end{array}$ & $\begin{array}{l}75 \mathrm{~g}, 2 \text { hours } \\
\text { fasting } \\
\text { glucose } \\
\text { tolerance test } \\
\text { (three levels) }\end{array}$ & $\begin{array}{l}\text { Fasting } \\
\geq 5.1 \mathrm{mmol} / \mathrm{L} \\
1 \text { hour } \\
\geq 10 \mathrm{mmol} / \mathrm{L} \\
2 \text { hours } \\
\geq 8.5 \mathrm{mmol} / \mathrm{L}\end{array}$ & $\begin{array}{l}75 \mathrm{~g}, 2 \text { hours } \\
\text { fasting glucose } \\
\text { tolerance test (two } \\
\text { levels) }\end{array}$ & $\begin{array}{l}\text { Fasting } \\
\geq 5.6 \mathrm{mmol} / \mathrm{L} \\
2 \text { hours } \\
\geq 7.8 \mathrm{mmol} / \mathrm{L}\end{array}$ \\
\hline
\end{tabular}

NICE, National Institute for Health and Care Excellence.

Outcome (HAPO) study, ${ }^{3}$ which was a large, prospective, observational study examining the influence of increasing blood glucose levels (BGLs) on a fasting glucose tolerance test (GTT) on eventual adverse pregnancy outcome.

Previously, diagnostic criteria for GDM in Australia were derived from an earlier ADIPS consensus statement published in $1991^{4}$ and re-endorsed in $1998^{5}$ (see table 1). It was based on the observed distributions of BGLs tested in pregnant women at various maternity centres. These older criteria had been widely used for the last two decades in many Australian maternity centres including our own.

Since the introduction of the new criteria, concerns have focused on the anticipated increase in annual incidence of GDM that these new criteria will cause and the resultant implications for workload. Early estimates of an annual increase of $35 \%{ }^{6}$ were followed by later data suggesting an almost doubling in some populations. ${ }^{7}$ Although many major maternity centres in Australia have adopted the new criteria, a 2016 survey found variable adoption in Australia ${ }^{8}$ and the criteria have not yet found international acceptance despite WHO endorsement. ${ }^{9-11}$

While it was never the intention of the HAPO authors to suggest a specific annual incidence for GDM, it is important to remember that the new criteria and the suggested relative risk reductions were derived from an untreated population. They were not derived from comparing the new criteria to any other existing methods of diagnosis. While the change may be important for uniformity in diagnosis and may result in clinically important outcomes in individuals previously not diagnosed with GDM, it is also important to assess whether any improvements are seen across large populations and, if so, whether they justify any increase in costs of care.

We aimed to estimate the impact of this change in a large tertiary maternity hospital by examining two prescreening cohorts of pregnant women immediately before and immediately after the new criteria were adopted. Specifically, we wished to examine the increase in annual incidence of GDM, assign an appropriate cost of care to the high-risk model employed for
GDM and compare this to any hospital-wide change in the HAPO outcomes on which the new criteria are based.

\section{PATIENTS AND METHODS}

As the new criteria for diagnosing GDM were introduced in our hospital in mid-2015, we selected 2014 as the last full calendar year of diagnosis under 1991/1998 ADIPS criteria $^{45}$ and 2016 as the first full year of diagnosis under the new IADPSG criteria. ${ }^{2}$ All women having care and delivering within the hospital were included for analysis, with exclusion limited only to pre-existing diabetes (ie, those who did not undergo screening for GDM) and multiple pregnancy (an exclusion criterion in the HAPO trial). Women in Australia have universal screening for GDM between 24 and 28 weeks.

Clinical care during the periods of study was divided into three groups: those without GDM, GDM managed with dietary measures and GDM requiring insulin. For occasions of clinical review, such as antenatal clinic consultations, group class and phone call consultations, and pregnancy day care admissions, cost was estimated from 'average occasion of service' figures for the relevant health professional, as collected by the institutional Business Performance Reporting Unit. The pharmacy schedule was consulted for the costs of consumables and medications. The Medicare Benefits Schedule was considered the most reproducible and valid estimation for the cost of ultrasound services. All costs were estimated in figures from the end of 2016, thus negating the need to adjust 2014 figures for Consumer Price Index or other potential inflationary changes.

Costs of inpatient care in our hospital consist mainly of 'bed-days' for the mother (increased mainly by caesarean section compared with vaginal birth) or admissions to special care nursery (SCN) or neonatal intensive care unit (NICU) for the infant. Inpatient costs were to be assessed if any differences were found in these two outcomes. The only difference in care for women with GDM compared with those without was a self-collected bidaily BGL 
for 1-2 days which was not deemed a significant enough cost for quantification.

Women diagnosed with GDM receive a 3-hour group class with a diabetes educator, dietician and physiotherapist. In addition, most have a follow-up one-on-one session with a dietician, phone consultations with diabetes educators, two extra antenatal clinics, assessment by consultant obstetricians rather than by midwives or junior medical staff and a growth ultrasound. They also require a glucometer and testing strips.

If dietary measures fail to control BGLs at acceptable levels, they also require insulin, a one-on-one session with a diabetes educator, an extra antenatal clinic, often a second growth scan and sometimes fetal heart rate monitoring via cardiotocography (CTG).

Demographic data were collected for each group, including age, body mass index, pre-existing polycystic ovarian syndrome (PCOS), smoking, parity and previous caesarean section (lower uterine caesarean section, LUSCS).

Primary outcomes were those on which the new criteria were based, namely caesarean section rates, hypertensive disorder of pregnancy, birth weight greater than the 90th percentile, preterm birth less than 37 weeks. $^{2}$

Additional maternal outcomes were induction of labour, instrumental birth, third degree tear and postpartum haemorrhage. Additional fetal outcomes were greater than the 95th percentile, less than the 10th percentile, admission to SCN or NICU, estimated gestational age, preterm birth less than 34 weeks, respiratory distress, jaundice requiring phototherapy, hypoglycaemia, stillbirth, neonatal death and Apgar score less than 7 at $5 \mathrm{~min}$. Birth trauma was initially included as an outcome but subsequently removed due to a change in coding practices midway through the study period which artificially lowered overall recorded rates.

Neonatal birth weights were plotted by percentile as described by the latest Australian birth charts. ${ }^{12}$ Neonatal hypoglycaemia was defined as any ward-measured BGL less than $2.6 \mathrm{mmol} / \mathrm{L}$.

Maternal and neonatal outcomes were examined for the entire hospital cohort (to examine the change as a hospital health policy) and for just women diagnosed with GDM in 2014 (before the change) compared with those in 2016 (after the change).

Data were collected prospectively by the institutional Quality and Safety Unit from the Maternity Care Information System (GE Healthcare, Little Chalfont, UK) and collated in MS Excel spreadsheets (Microsoft, Redmond, USA). Data were analysed after selecting the demographics and outcomes of interest. Maternal and neonatal characteristics were compared using descriptive statistics. Discrete variables are reported in the tables as total numbers with percentage in parentheses and continuous variables are reported as the mean with 95\% CIs in parentheses. For univariate analyses, discrete variables were analysed using Fisher's exact test or Pearson's $\chi^{2}$ test and continuous variables using Student's t-test. Multivariate analysis with logistic regression was planned for any outcome which met statistical and clinical significance and had documented risk factors other than

\begin{tabular}{|c|c|c|c|}
\hline & 2014 & 2016 & $P$ value \\
\hline $\begin{array}{l}\text { Total } \\
\text { deliveries }\end{array}$ & 7010 & 7488 & $\mathrm{~N} / \mathrm{a}$ \\
\hline Age (year) & $30.9(30.8-31.0)$ & $31.2(31.1-31.3)$ & 0.0016 \\
\hline $\begin{array}{l}\text { Body mass } \\
\text { index }(\mathrm{kg} / \\
\left.\mathrm{m}^{2}\right)\end{array}$ & $24.8(24.7-24.9)$ & $24.7(24.6-24.8)$ & 0.28 \\
\hline $\begin{array}{l}\text { Polycystic } \\
\text { ovarian } \\
\text { syndrome }\end{array}$ & 110 (1.57\%) & $151(2.02 \%)$ & 0.043 \\
\hline Smoking & $326(4.65 \%)$ & 303 (4.05\%) & 0.075 \\
\hline Parity $\geq 1$ & 3228 (46.1\%) & 3365 (44.9\%) & 0.18 \\
\hline $\begin{array}{l}\text { Previous } \\
\text { LUSCS }\end{array}$ & $960(13.7 \%)$ & 1027 (13.7\%) & 0.45 \\
\hline
\end{tabular}

GDM. P values are reported in the final column of all tables with less than 0.05 considered statistically significant and highlighted in bold. Statistical analysis was performed using STATA V.9.2 (StataCorp).

\section{Patient and public involvement}

This was an anonymised retrospective audit, thus, patients and the public were not required to be directly involved in recruitment or conduct of the study. Indeed, emphasis was given towards assessing the implications of this clinical health policy on a patient cohort as a whole rather than subgroup or individual outcomes.

\section{RESULTS}

\section{Demographics and health outcomes}

In 2014, there were 7010 pregnant women of whom 416 were diagnosed with GDM (incidence 5.93\%) and in 2016, there were 7488 pregnant women of whom 774 were diagnosed with GDM (incidence 10.3\%). The demographics of the two cohorts are shown in table 2.

Although the second cohort was statistically significantly older, this was only by a mean of 4 months. The diagnosis of PCOS was higher but overall rates were low and possibly under-reported. These two findings were statistically significant but unlikely to be clinically relevant. The relative increase of $73.7 \%$ in the annual incidence of GDM is most likely attributable to the change in diagnosis rather than to any changed demographic factors.

The maternal outcomes for the entire cohort are shown in table 3 and the fetal outcomes in table 4, with the HAPO/IADPSG outcomes highlighted in bold.

Following the introduction of the new GDM criteria, there has not appeared to be a hospital-wide decrease in the main outcomes reported in the subanalysis of the HAPO study, most particularly in birth weight $>90$ th percentile for gestation, caesarean section, hypertensive disorder of pregnancy or preterm birth $<37$ weeks. However, there has been a hospital-wide decrease in neonatal death and birth weight greater than the 95th percentile in the fetal outcomes and an increase in 
Table 3 Overall maternal outcomes in 2014 and 2016

\begin{tabular}{lrrl}
\hline & 2014, n (\%) & 2016, n (\%) & P value \\
\hline $\begin{array}{l}\text { Hypertensive } \\
\text { disorder }\end{array}$ & $332(4.74)$ & $361(4.82)$ & 0.81 \\
$\begin{array}{l}\text { Induction of } \\
\text { labour }\end{array}$ & $2407(34.3)$ & $2725(36.4)$ & $\mathbf{0 . 0 1}$ \\
$\begin{array}{l}\text { Overall LUSCS rate } \\
\quad 1963(28.0)\end{array}$ & $2070(27.6)$ & 0.63 \\
$\begin{array}{l}\text { Emergency } \\
\text { LUSCS rate }\end{array}$ & $1088(15.5)$ & $1076(14.3)$ & 0.05 \\
$\begin{array}{l}\text { Instrumental birth } \\
\text { Third degree tear }\end{array}$ & $21316(18.8)$ & $1513(20.2)$ & 0.03 \\
\hline PPH & $1685(24.0)$ & $197(2.6)$ & 0.09 \\
\hline
\end{tabular}

$\mathrm{PPH}$, post-partum haemorrhage.

induction of labour and instrumental birth in the maternal outcomes. The decrease in neonatal death rates was unexplained, almost always occurs at the extreme of prematurity and the absolute difference was low at $0.2 \%$. The change most likely attributable to tightening GDM diagnoses is a small reduction in very large babies.

The maternal and fetal outcomes for the women with GDM are shown in tables 5 and 6 , respectively. There was a reduction in the annual incidence of third degree tears from $5.29 \%$ to $2.58 \%$ in the mothers with GDM. There was also a reduction in the incidence of neonatal hypoglycaemia (from $9.62 \%$ to $5.94 \%$ ) and admissions to SCN (from $12.5 \%$ to $7.75 \%$ ).

\section{Costs of care}

The average antenatal care package for women without GDM costs AUD $\$ 923$ and for the $15 \%$ that require postdates care this is AUD $\$ 1742$ (when extra clinics, and
Table 5 Maternal outcomes of women with gestational diabetes mellitus in 2014 compared with 2016

\begin{tabular}{|c|c|c|c|}
\hline & 2014 & 2016 & $P$ value \\
\hline Total & $n=416,(\%)$ & $n=774,(\%)$ & $\mathrm{N} / \mathrm{A}$ \\
\hline $\begin{array}{l}\text { Hypertensive } \\
\text { disorder }\end{array}$ & $20(4.80)$ & 35 (4.52) & 0.85 \\
\hline Induction of labour & $204(49.0)$ & $379(49.0)$ & 0.98 \\
\hline Overall LUSCS rate & $162(38.9)$ & 289 (37.3) & 0.59 \\
\hline $\begin{array}{l}\text { Emergency } \\
\text { LUSCS rate }\end{array}$ & $71(17.1)$ & $121(15.6)$ & 0.52 \\
\hline Instrumental birth & $83(20.0)$ & $134(17.3)$ & 0.26 \\
\hline Third degree tear & 22 (5.29) & $20(2.58)$ & 0.016 \\
\hline $\mathrm{PPH}$ & $121(29.1)$ & $205(26.5)$ & 0.34 \\
\hline
\end{tabular}

CTG and amniotic fluid monitoring are required). The care package for women with GDM who do not need insulin is AUD\$2026 and for those that do need insulin is AUD\$2534 (or AUD\$3826 if CTG monitoring from 36 weeks is undertaken: on audit during the study period, this occurred in $50 \%$ of patients).

In 2014, 210 women with GDM were controlled with dietary measures and 206 required insulin. The cost of care for GDM was calculated as follows:

GDM diet controlled:

$$
210 \times \$ 2026=\$ 425460
$$

GDM insulin controlled:

$$
0.5 \times 206 \times \$ 2534+0.5 \times 206 \times \$ 3826=\$ 655080
$$

Total $=$ US\$1 080540.

\begin{tabular}{|c|c|c|c|}
\hline & 2014 & 2016 & $P$ value \\
\hline Stillbirth & $36(0.51 \%)$ & $40(0.53 \%)$ & 0.86 \\
\hline Hypoglycaemia & $154(2.20 \%)$ & $170(2.27 \%)$ & 0.77 \\
\hline Respiratory distress & $140(2.00 \%)$ & $170(2.27 \%)$ & 0.26 \\
\hline Apgar $<7$ at $5 \mathrm{~min}$ & $280(3.99 \%)$ & $286(3.82 \%)$ & 0.59 \\
\hline Birth $<37$ weeks & $645(9.20 \%)$ & $671(8.96 \%)$ & 0.62 \\
\hline Birth $<34$ weeks & $292(4.17 \%)$ & $325(4.34 \%)$ & 0.61 \\
\hline Shoulder dystocia & $102(1.46 \%)$ & $131(1.75 \%)$ & 0.16 \\
\hline Admission to neonatal intensive care unit & $320(4.56 \%)$ & $366(4.89 \%)$ & 0.36 \\
\hline Birth weight $>95 \%$ & $300(4.31 \%)$ & $269(3.61 \%)$ & 0.03 \\
\hline Birth weight $>90 \%$ & $577(8.28 \%)$ & $586(7.86 \%)$ & 0.36 \\
\hline Birth weight $<10 \%$ & $570(8.18 \%)$ & $616(8.27 \%)$ & 0.85 \\
\hline
\end{tabular}

Table 4 Overall fetal outcomes in 2014 and 2016 
In 2016, 413 women with GDM were controlled with dietary measures and 361 required insulin. The cost of care for GDM was calculated as follows:

GDM diet controlled:

$$
413 \times \$ 2026=\$ 836738
$$

GDM insulin controlled:

$$
0.5 \times 361 \times \$ 2534+0.5 \times 361 \times \$ 3826=\$ 1147980
$$

Total $=$ US\$1 984718 .

The gross cost increase for care of women with GDM was thus AUD $\$ 904$ 178. The net cost increase can be determined by attributing the cost of standard care to the excess diagnoses of GDM. If we round the incidence of GDM in 2014 up to $6 \%$ and use this with the total number of deliveries in $2016(n=7420)$, the approximate number of women diagnosed with GDM if the criteria did not change would have been: $0.06 \times 7420=445$. The approximate excess number of cases of GDM is the total in $2016(\mathrm{n}=774)$ minus this figure $(\mathrm{n}=445)$ which is: $774-445=329$. We can then apply this number to routine care (bearing in mind $15 \%$ of those undergoing routine care require postdates monitoring) as follows:

\section{$0.85 \times 329 \times \$ 923+0.15 \times 329 \times \$ 1742=\$ 344085$}

The net cost, which represents the change in antenatal resources, is then the gross cost increase minus this figure:

$$
\$ 904178-\$ 344085=\$ 560093
$$

The hospital has thus spent approximately AUD $\$ 560$ 093 caring for women with GDM because of the change in criteria.

\section{DISCUSSION}

$\mathrm{HAPO}^{3}$ was a landmark study for several reasons, namely its sheer size (over 25000 pregnant women), its robust statistical methods, and its aim to unify disparate international views about the significance of GDM and the best way to diagnose it. The IADPSG subanalysis ${ }^{2}$ used important clinical outcomes in identifying a 'best fit' for cut-off values within the $75 \mathrm{~g}$ GTT to diagnose GDM: most are routinely measured in clinical care (with the exception of cord C-peptide and fetal fat distribution). The resulting recommendation was for a $75 \mathrm{~g}$ GTT for all women (regardless of baseline risk) with levels of greater than $5.1 \mathrm{mmol} / \mathrm{L}$ at fasting, $10 \mathrm{mmol} / \mathrm{L}$ at 1 hour and $8.5 \mathrm{mmol} / \mathrm{L}$ at 2 hours considered diagnostic.

Despite a WHO statement endorsing the new criteria, ${ }^{13}$ there has been a failure of international acceptance to screen for GDM in this way. The National Institute for Health and Care Excellence which guides care in the UK is perhaps the most striking example, recommending only screening those patients with risk factors and using levels of greater than or equal to $5.6 \mathrm{mmol} / \mathrm{L}$ at fasting and $7.8 \mathrm{mmol} / \mathrm{L}$ at 2 hours. ${ }^{9}$ A sophisticated economic evaluation found this approach to be superior in their population, ${ }^{14}$ and an earlier economic evaluation found that it was not currently cost-effective to routinely identify pregnant women for hyperglycaemia. ${ }^{15}$ This latter also suggested further research into longer term health outcomes of women and babies affected by GDM and more cost-effective ways of treating GDM, a senti-

\begin{tabular}{|c|c|c|c|}
\hline & 2014 & 2016 & $P$ value \\
\hline EGA & $37.8(37.6-38.1)$ & 38.0 (37.9-38.2) & 0.13 \\
\hline Stillbirth & $5(1.20 \%)$ & $3(0.39 \%)$ & 0.10 \\
\hline Hypoglycaemia & 40 (9.62\%) & 46 (5.94\%) & 0.02 \\
\hline Respiratory distress & $11(2.64 \%)$ & $12(1.55 \%)$ & 0.19 \\
\hline Apgar $<7$ at 5 min & $19(4.57 \%)$ & $26(3.36 \%)$ & 0.30 \\
\hline Birth $<37$ weeks & $51(12.3 \%)$ & $83(10.7 \%)$ & 0.42 \\
\hline Birth $<34$ weeks & $25(6.01 \%)$ & $30(3.88 \%)$ & 0.10 \\
\hline Shoulder dystocia & $7(1.68 \%)$ & $5(0.65 \%)$ & 0.09 \\
\hline Admission to neonatal intensive care unit & $27(6.49 \%)$ & $39(5.04 \%)$ & 0.30 \\
\hline Birth weight >95\% & 27 (6.49\%) & $35(4.52 \%)$ & 0.15 \\
\hline Birth weight $>90 \%$ & $48(11.5 \%)$ & 74 (9.56\%) & 0.28 \\
\hline Birth weight $<10 \%$ & 38 (9.13\%) & $60(7.75 \%)$ & 0.41 \\
\hline
\end{tabular}
ment reiterated by the findings of our manuscript.

Table 6 Fetal outcomes of women with gestational diabetes mellitus in 2014 compared with 2016

Bold numbers indicate statistical significance. Bold words are HAPO-outcomes.

EGA, estimated gestational age; NND, neonatal death. 
Economic evaluations in American populations have also tended to favour existing screening criteria, ${ }^{16-18}$ although with less robust methodology and with different existing screening methods to both the UK and Australia. The latest Cochrane review concluded that there is insufficient evidence to prefer any particular screening method for GDM over another. ${ }^{19}$

The new criteria were a major change to established practice in Australia. The abolition of the non-fasting glucose challenge test (GCT) and the introduction of the 1-hour BGL on the GTT were both new. The fasting BGL was tightened from greater than or equal to $5.5-5.1 \mathrm{mmol} / \mathrm{L}$ and the 2-hour level eased from greater than or equal to $8.0-8.5 \mathrm{mmol} / \mathrm{L}$. Some studies have tried to examine outcomes in patients who may have been diagnosed with GDM under the new system but not under the old.$^{20-22}$ Generally, they have reported groups at higher risk of adverse outcome (particularly caesarean section and large babies) who may have been previously underdiagnosed, but such an approach is flawed because of the abolition of the GCT and the introduction of the previously untested 1-hour BGL. It thus is not possible to retrospectively examine the outcomes of those who may have had a false negative on the GCT or those who may have only tested positive on the new 1-hour level. Unfortunately, this is a major inherent weakness in all studies retrospectively examining GDM when screening is changed (rather than modified) and would only be overcome by a large prospective study examining two different systems of diagnosis. This would require at least multicentre or more likely international collaboration to recruit suitable numbers: a prospect which seems unlikely given the international disagreement over different diagnostic criteria and the immense time and planning a trial with somewhat similar methodology (although with two groups for comparison) to the HAPO study would require.

A separate approach, one adopted by this study, is to quantify any overall changes in clinical outcomes and attribute a cost to the increased burden of care and to identify any overall outcome improvements.

The strengths of this study include using a single, large, tertiary centre with a uniform urban catchment area and relatively stable demographics over the study period. The numbers were large with over 7000 births per year in each cohort, and the costs of care were quantifiable by an established institutional Business Performance Reporting Unit. Outcomes were readily identified from existing data management systems and were usually categorical (often binary) and not requiring extensive further investigation or statistical analysis.

The weaknesses of the study are those always inherent within retrospective data, including the potential for treatment or ascertainment bias. Retrospectively comparing two large cohorts with different methodologies for diagnosis will always carry greater uncertainty than usual when compared with well-designed prospective trials. As it is impossible to determine which of the 2014 'screen-negative' cohort would screen-positive under new criteria (and vice versa), many assumptions about the background demographic being the same must be made. As we examined a large cohort, within a single centre, with strict zoning boundaries which did not change between the 2 years and with an analysis of all feasibly collected background data, we have attempted to satisfy the assumption of equal demographics but this will always remain an uncertainty.

We demonstrated a relative increased incidence of GDM of $74 \%$, but we were unable to demonstrate any statistically significant improvements in major outcomes across the hospital as a whole. There was possibly a small improvement in the incidence of very large babies (greater than the 95th percentile) but the change was small $(0.7 \%)$ and there was no change in babies greater than the 90th percentile. An apparent improvement in birth trauma was due to a change in coding practices (and removed as an outcome), and an improvement in the neonatal death rate was unexplained but very low in absolute terms $(0.2 \%)$. This latter tended to be confined to babies of extreme prematurity born well before routine screening for GDM. It is important to note that these findings, in a retrospective analysis, may be subject to unrecognised selection bias or confounding and form part of a larger debate into the care for women with GDM.

It may be reasonable to hypothesise that, with such minimal overall hospital-wide changes, that it is simply a lower risk cohort being now diagnosed with GDM. This is somewhat, but not completely, borne out by analysing the same outcomes in women with GDM before and after the change. While major outcomes such as caesarean section rates, hypertensive disorders, preterm birth and macrosomia have seemingly not changed, there has been a reduction in third degree tears and a substantial decrease in the number of babies diagnosed with hypoglycaemia and admitted to SCN. This is suggestive of an increase in diagnoses represented by women on the milder end of the spectrum of GDM.

We have also demonstrated an increase in net costs of over AUD $\$ 500000$ per annum. This is primarily due to employing a 'high-risk' model of care to all women with GDM. As no overall changes were discovered in mode of delivery or admission to NICU/SCN, inpatient costs were not examined. In smaller cohorts, especially those analysed prospectively, it would be worthwhile to examine patient-level data and directly assign costs of care in both the antenatal and immediate postpartum period. Some outcome differences noted in tables 5 and 6 in the outcomes of screen-positive women would be accounted for in such prospective data and unrecognised variation in costs (including inpatient care) may come to light. While the overall costs are seemingly not redeemed in the short term by marked improved outcomes, there may be unquantified health outcomes demonstrable in longer term analysis of women with GDM and their babies treated under this system. 
While the new criteria are laudable in their efforts at uniformity of diagnosis and adverse outcome avoidance, and possibly have improved clinical outcomes in subgroups of women previously not diagnosed with GDM, there is lack of quality evidence supporting their superiority over other systems of diagnosis. Thus, further research is needed in three main areas. First, it would be desirable to have prospective (and ideally randomised controlled trial) evidence examining the impact of this system of diagnosis over others employed around the world. Second, long-term outcomes of the women with GDM and their children may uncover health benefits not accounted for in immediate analyses like those presented in this study, for instance, with improvements in childhood obesity rates. There may indeed be quantifiable cost savings that can be compared with the initial increase in costs of care but appropriate budgetary measures to ensure the initial hospitals of care are adequately reimbursed are essential. Finally, it is important to investigate more economic ways of antenatally managing women with GDM particularly in the lower risk group, for example, those easily controlled with simple dietary measures or the increasing use of metformin in those currently being prescribed insulin.

\section{CONCLUSION}

The annual incidence of GDM has immediately and markedly increased due to the change in diagnostic criteria with an increase in cost of care and with seemingly no clear changes in immediate clinical outcomes. Most particularly, macrosomia rates ( $>90$ th percentile), caesarean section rates and preterm birth less than 37 weeks remain unchanged. We suggest that these results add weight to the need for longer term data before confirming that HAPO/IADPSG criteria are superior to other systems of diagnosis. Such data would need to be derived from cohorts undergoing universal routine screening with these criteria, and quantifiable health benefits compared against increases in immediate costs of care such as we report here.

Contributors The corresponding author (TC) was responsible for the study design, literature review, collection and analysis of data, interpretation of clinical findings, writing of the manuscript and decision for submission. TC is responsible for the overall content and acts as guarantor. SPB supervised the project and contributed to all of the above in a consulting role. AP contributed to planning and executing appropriate statistical analysis and with interpretation of the data. All authors contributed to the final manuscript review and final submission.

Funding The Royal Australian and New Zealand College of Obstetrics and Gynaecology, who awarded the Luke Proposch Perinatal Research Scholarship to the corresponding author to financially support this research. The corresponding author had full access to the data in the study and final responsibility for the decision to submit for publication.

Disclaimer This had no role in the study design, data collection, analysis and interpretation, writing of the report or decision to submit for publication.

Competing interests None declared.

Patient consent for publication Not required.
Ethics approval The study was approved as an anonymised audit by the Institutional Research and Ethics Committee with identifying information removed before analysis.

Provenance and peer review Not commissioned; externally peer reviewed. Data sharing statement There are no unpublished data from the study.

Open access This is an open access article distributed in accordance with the Creative Commons Attribution Non Commercial (CC BY-NC 4.0) license, which permits others to distribute, remix, adapt, build upon this work non-commercially, and license their derivative works on different terms, provided the original work is properly cited, appropriate credit is given, any changes made indicated, and the use is non-commercial. See: http://creativecommons.org/licenses/by-nc/4.0/.

\section{REFERENCES}

1. ADIPS Consensus Guidelines for the Testing and Diagnosis of Hyperglycaemia in Pregnancy in Australia and New Zealand. wwwadipsorgau (accessed Jan 2018). 2014.

2. Metzger BE, Gabbe SG, Persson B, et al. International association of diabetes and pregnancy study groups recommendations on the diagnosis and classification of hyperglycemia in pregnancy. Diabetes Care 2010;33:e98-82.

3. Metzger BE, Lowe LP, Dyer AR, et al. Hyperglycemia and adverse pregnancy outcomes. N Engl J Med 2008;358:1991-2002.

4. Martin FI, Vogue A, Dargaville R, et al. The diagnosis of gestational diabetes. Med J Aust 1991;155:112.

5. Hoffman L, Nolan C, Wilson JD, et al. Gestational diabetes mellitusmanagement guidelines. The Australasian Diabetes in Pregnancy Society. Med J Aust 1998;169:93-7.

6. Moses RG, Morris GJ, Petocz P, et al. The impact of potential new diagnostic criteria on the prevalence of gestational diabetes mellitus in Australia. Med J Aust 2011;194:338-40.

7. Wong VW, Lin A, Russell H. Adopting the new World Health Organization diagnostic criteria for gestational diabetes: How the prevalence changes in a high-risk region in Australia. Diabetes Res Clin Pract 2017;129:148-53.

8. Flack JR, Ross GP. Survey on testing for gestational diabetes mellitus in Australia. Aust N Z J Obstet Gynaecol 2016;56:346-8.

9. National Institute for Health and Care Excellence. https://pathways. nice.org.uk/pathways/diabetes-in-pregnancy 2016 (accessed January 2018).

10. American Diabetes Association. 2. Classification and Diagnosis of Diabetes. Diabetes Care 2016;39 Suppl 1(Suppl 1):S13-S22.

11. Canadian Diabetes Association Clinical Practice Guidelines Expert Committee. Thompson D, Berger H, Feig D, et al. Diabetes and pregnancy. Can J Diabetes 2013;37(Suppl 1):S168-83.

12. Dobbins TA, Sullivan EA, Roberts CL, et al. Australian national birthweight percentiles by sex and gestational age, 1998-2007. Med $J$ Aust 2012;197:291-4.

13. Diagnostic criteria and classification of hyperglycaemia first detected in pregnancy: a World Health Organization Guideline. Diabetes Res Clin Pract 2014;103:341-63.

14. Jacklin PB, Maresh MJ, Patterson CC, et al. A cost-effectiveness comparison of the NICE 2015 and WHO 2013 diagnostic criteria for women with gestational diabetes with and without risk factors. BMJ Open 2017;7:e016621.

15. Farrar D, Simmonds M, Griffin S, et al. The identification and treatment of women with hyperglycaemia in pregnancy: an analysis of individual participant data, systematic reviews, meta-analyses and an economic evaluation. Health Technol Assess 2016;20:1-348.

16. Basevi V, Di Mario S, Morciano C, et al. Comment on: American Diabetes Association. Standards of medical care in diabetes--2011. Diabetes Care 2011;34(Suppl. 1):S11-S61. Diabetes Care 2011;34:e53.

17. Ohno MS, Sparks TN, Cheng YW, et al. Treating mild gestational diabetes mellitus: a cost-effectiveness analysis. Am J Obstet Gynecol 2011;205:282.e1-282.e7.

18. Lee GT, Satyan MT, Grothusen JD, et al. A retrospective study comparing outcomes in a midwestern US population after introduction of IADPSG guidelines for gestational diabetes. The journal of maternal-fetal \& neonatal medicine 2017:1-6.

19. Farrar D, Duley L, Dowswell T, et al. Different strategies for diagnosing gestational diabetes to improve maternal and infant health. Cochrane Database Syst Rev 2017;8:CD007122.

20. Laafira A, White SW, Griffin CJ, et al. Impact of the new IADPSG gestational diabetes diagnostic criteria on pregnancy outcomes in Western Australia. Aust N Z J Obstet Gynaecol 2016;56:36-41. 
21. Jiang S, Chipps D, Cheung WN, et al. Comparison of adverse pregnancy outcomes based on the new IADPSG 2010 gestational diabetes criteria and maternal body mass index. Aust N Z J Obstet Gynaecol 2017;57:533-9.
22. Abell SK, Teede HJ. The IADPSG diagnostic criteria identify women with increased risk of adverse pregnancy outcomes in Victoria. Aust N Z J Obstet Gynaecol 2017;57:564-8. 